\title{
PENGARUH BRAND AWARENESS DAN PERCEIVED QUALITY TERHADAP PURCHASE INTENTION: BRAND LOYALTY SEBAGAI VARIABEL MEDIASI
}

\author{
Alexandra Fenetta \\ Program Studi Magister Manajemen Universitas Tarumanagara \\ xandrafenetta@gmail.com \\ Keni \\ Program Studi Magister Manajemen Universitas Tarumanagara \\ Masuk : 07-12-2019, revisi : 20-12-2019 diterima untuk diterbitkan : 20-12-2019
}

\begin{abstract}
The aim of this study are: first, to explore the effects of brand awareness, perceived quality and brand loyalty on purchase intention. Second, to explore the effects of brand awareness and perceived quality on brand loyalty. Third, to find out the effects of brand awareness and perceived quality on purchase intention if mediated by brand loyalty. The samples that are used in the research are 150 respondents in Jakarta conducted by convenience sampling. The data techniques are processed using structural equation modelling on software SmartPLS 3.2.8. The results of this research are: first, brand awareness and perceived quality do not have a positive impact on purchase intention, yet brand loyalty has a positive impact on purchase intention. Second, brand awareness and perceived quality have a positive on brand loyalty. Third, brand awareness and perceived quality have a positive impact on purchase intention if mediated by brand loyalty.
\end{abstract}

Abstrak : Tujuan dari penelitian adalah pertama, untuk menguji efek dari brand awareness, perceived quality dan brand loyalty terhadap purchase intention. Kedua, untuk menguji efek dari brand awareness dan perceived quality terhadap purchase intention. Ketiga, untuk mengetahui efek dari brand awareness dan perceived quality terhadap purchase intention jika dimediasi oleh brand loyalty. Sampel dalam penelitian ini yaitu 150 responden di Jakarta yang diambil melalui convenience sampling. Teknik pengolahan datd dengan model persamaan stuktural melalui software SmartPLS 3.2.8. Hasil yang ditemukan pertama, brand awareness dan perceived quality tidak berpengaruh positif terhadap purchase intention, tetapi brand loyalty berpengaruh positif terhadap purchase intention. Kedua, brand awareness dan perceived quality berpengaruh positif terhadap brand loyalty. Ketiga, brand awareness dan perceived quality berpengaruh positif terhadap purchase intention jika dimediasi oleh brand loyalty.

Keywords : Brand Awareness, Perceived Quality, Brand Loyalty, Purchase Intention.

\section{PENDAHULUAN}

Persaingan pasar obat OTC (Over The Counter) yang semakin bertumbuh membuat daya saing penjualan akan produk obat OTC semakin tinggi. Kondisi ini mendorong perusahaan untuk menunjukkan keunggulan produk OTC sebagai kekuatan dan daya saing penjualan. Suatu perusahaan harus membangun strategi yang kuat untuk meningkatkan purchase intention dalam menghadapi kompetitornya. Purchase intention adalah "A kind of decision in which studied why a customer purchases a brand in particular" (Shah et al., 2012:107). Purchase intention adalah tingkat ukur bagi konsumen untuk melakukan pembelian merek tertentu.

Chi et al. (2009) yang menyatakan bahwa brand awareness dapat mempengaruhi purchase intention. Merek yang semakin dikenal oleh konsumen dapat meningkatkan intensitas pembelian konsumen akan merek itu. Tingkat familiar akan suatu merek dapat dipengaruhi dari informasi yang muncul di benak konsumen. 
Aaker (2008) menyatakan perceived quality mempengaruhi purchase intention. Dengan memiliki perceived quality yang tinggi dapat memberi keuntungan bagi produk yang dijual. Hal ini tercermin ketika produk yang ditawarkan memiliki keunggulan di dalam kualitasnya

Sumarwan (2015) menyatakan brand loyalty dapat mempengaruhi purchase intention. Brand loyalty merupakan keinginan kuat yang dimiliki konsumen terhadap merek sehingga menimbulkan keterikatan dan keterlibatan merek pada jangka waktu yang panjang. Timbulnya keterlibatan yang positif terhadap merek akan mempengaruhi minat pembelian konsumen. Berdasarkan latar belakang tersebut, tujuan dari penelitian ini adalah untuk meneliti pengaruh brand awareness dan perceived quality terhadap purchase intention: brand loyalty sebagai variabel mediasi.

\section{TELAAH KEPUSTAKAAN Brand Awareness}

Menurut Keller (2013:72), brand awareness adalah "the strength of the brand node or trace in memory measuring the consumer's ability to identify the brand under different conditions". Surachman (2008:7) berpendapat "brand awareness adalah tingkat penerimaan awal dari seseorang ketika melihat atau mendengar suatu informasi tentang mereknya". Karam dan Saydam (2015:67) berpendapat "the brand awareness can be created through the presentation of brands to the customers developing the stimuli like response to relate, recognize, recall, and be on the whole aware of brands". Kesimpulannya, brand awareness adalah kesadaran merek tercipta melalui rangsan informasi yang diperoleh sehingga eksistensinya dapat mempengaruhi rangsangan konsumen untuk terhubung, mengenal, mengingat hingga menyadari merek tersebut.

\section{Perceived Quality}

Menurut Tuan dan Premkumar (2017:132), perceived quality yaitu "the customer's feeling of the overall quality or superiority of a product or service with respect to its intended purpose related to alternatives and with creating the powerful brand loyalty". Schiffman dan Wisenblit (2015:137) menyatakan "the perceived quality of products and services is based on a variety of informational cues that consumers associate with the offerings.". Durianto dkk (2001:196) berpendapat "persepsi kualitas menentukan nilai dari produk atau jasa dan berpengaruh langsung terhadap keputusan pembelian dan loyalitas konsumen". Kesimpulannya, perceived quality yaitu persepsi konsumen terhadap kualitas barang atau jasa umumnya direlasikan dengan informasi yang didapat. sehingga mempengaruhi minat pembelian dan loyalitas konsumen itu sendiri.

\section{Brand Loyalty}

Khan dan Mahmood (2012:33) menjelaskan brand loyalty sebagai "the customer's unconditional commitment and a strong relationship with the brand". Schiffman dan Wisenblit (2015:168) menambahkan "brand loyalty is a measure of how often consumers buy a given brand, whether or not they switch the brands and, if they how often, and the extent of their commitment to buying the brand regularly". Selvrajah (2018:202) menyatakan "brand loyalty is the positive feelings of consumer on the brand and the intense dedication to keep repeated purchase the same product or services". Kesimpulannya, brand loyalty adalah perasaan positif akan merek yang terbentuk untuk menunjukkan komitmen konsumen dalam melakukan pembelian berulang serta mengukur intensitas perpindahan konsumen akan merek kompetitor.

\section{Purchase Intention}

$\mathrm{Wu}$ et al (2011:32) menyatakan "Purchase intention represents the possibility that consumers will plan a certain product or service in the future". Durianto dan Liana (2004:4) menjelaskan "minat beli adalah sesuatu yang berhubungan dengan rencana konsumen untuk membeli produk tertentu dan seberapa banyak unit produk yang dibutuhkan pada periode tertentu". Belch dan Belch (2015:24) juga berpendapat "purchase intention is generally based on matching of purchase motives with attribute or characteristic of brand user consideration". 
Kesimpulannya, purchase intention adalah proses ketika konsumen memiliki keinginan pembelian di masa mendatang atas motivasi tertentu dengan menentukan jenis produk yang dibeli serta kuantitas produk di masa tertentu.

\section{KAITAN ANTAR VARIABEL}

\section{Pengaruh Brand Awareness terhadap Purchase Intention}

Monareh dan Wiryawan (2012) menyatakan kesadaran merek akan menunjukkan seberapa besar sikap konsumen melakukan pembelian akan merek tersebut. Suatu minat pembelian nantinya akan dipengaruhi seberapa tinggi konsumen familiar akan merek tersebut. Berdasarkan pernyataan tersebut, maka hipotesis penelitian adalah sebagai berikut:

$\mathrm{H}_{1}$ : Brand awareness memiliki pengaruh secara positif terhadap purchase intention.

\section{Pengaruh Perceived Quality terhadap Purchase Intention}

Bilal dan Ali (2013) juga menambahkan intensi konsumen dalam membeli suatu produk akan meningkat jika kualitas produk yang dipersepsikan tersebut tinggi. Persepsi kualitas yang baik meningkatkan minat pembelian jika konsumen mendapatkan nilai dari suatu produk seperti yang dipersepsikan. Berdasarkan pernyataan tersebut, maka hipotesis penelitian adalah sebagai berikut:

$\mathrm{H}_{2}$ : Perceived quality memiliki pengaruh secara positif terhadap purchase intention.

\section{Pengaruh Brand Awareness terhadap Brand Loyalty}

Dhurup et al. (2014) dan Andervazh et al. (2016) menyatakan semakin besar konsumen mengenal suatu merek, maka semakin besar konsumen membangun kedekatannya terhadap merek tersebut, sehingga mendorong konsumen untuk loyal terhadap merek itu. Peran brand yang terbentuk di dalam pikiran konsumen dipengaruhi berdasarkan pengetahuan, kesadaran serta pengalaman akan brand tersebut. Berdasarkan pernyataan tersebut, maka hipotesis penelitian adalah sebagai berikut:

$\mathrm{H}_{3}$ : Brand awareness memiliki pengaruh secara positif terhadap brand loyalty.

\section{Pengaruh Perceived Quality terhadap Brand Loyalty}

Foroudi et al. (2018) berpendapat bahwa ketika konsumen memiliki perceived quality yang tinggi terhadap suatu merek, situasi ini dapat mempengaruhi preferensi konsumen dan membentuk loyalitas konsumen akan merek itu. Perceived quality dapat mendorong pikiran konsumen untuk membangun kedekatan konsumen dengan brand tersebut. Berdasarkan pernyataan tersebut, maka hipotesis penelitian adalah sebagai berikut:

$\mathrm{H}_{4}$ : Perceived quality memiliki pengaruh secara positif terhadap brand loyalty.

\section{Pengaruh Brand Loyalty terhadap Purchase Intention}

Meilani (2017) berpendapat semakin tinggi konsumen loyal terhadap merek, semakin tinggi minat pembelian konsumen akan merek tersebut. Loyalitas merek dapat memberikan pengaruh yang kuat dalam minat pembelian di masa yang akan mendatang. Konsumen yang telah loyal akan merek tertentu akan cenderung sulit untuk berpindah ke merek lain. Berdasarkan pernyataan tersebut, maka hipotesis penelitian adalah sebagai berikut:

$\mathrm{H}_{5}$ : Brand loyalty memiliki pengaruh secara positif terhadap purchase intention.

\section{Pengaruh Brand Awareness terhadap Purchase Intention melalui Brand Loyalty sebagai} variabel mediasi

Chi et al. (2009) berpendapat bahwa brand awareness memiliki pengaruh besar terhadap brand loyalty serta berpengaruh besar terhadap purchase intention. Brand yang dikenal oleh konsumen menumbuhkan preferensi untuk menggunakan brand tersebut serta mempengaruhi tingkat loyalitas terhadap brand. Loyalitas merek dapat dipengaruhi salah satunya jika suatu brand memiliki tingkat kesadaran merek yang tinggi serta image yang baik bagi konsumen. Semakin tinggi tingkat loyalitas maka akan semakin tinggi minat pembelian berulang akan merek yang sama di masa mendatang. Berdasarkan pernyataan tersebut, maka hipotesis penelitian adalah sebagai berikut:

$\mathrm{H}_{6}$ : Brand awareness memiliki pengaruh secara positif terhadap purchase intention jika 
dimediasi oleh brand loyalty.

\section{Pengaruh Perceived Quality terhadap Purchase Intention melalui Brand Loyalty sebagai variabel mediasi}

Muslim dan Qur'anis (2017) berpendapat perceived quality berpengaruh terhadap brand loyalty serta dapat meningkatkan purchase intention. Perceived quality mempengaruhi minat pembelian ketika kualitas yang dipersepsikan diterima baik di benak konsumen. Perceived quality menampilkan value merek sehingga mempengaruhi kekuatan hubungan antara konsumen dengan merek tersebut. Tingkat kedekatan konsumen membentuk tingkat loyalitas merek serta mempengaruhi minat pembelian itu. Berdasarkan pernyataan tersebut, maka hipotesis penelitian adalah sebagai berikut:

$\mathrm{H}_{7}$ : Perceived quality memiliki pengaruh secara positif terhadap purchase intention jika dimediasi oleh brand loyalty.

\section{METODOLOGI PENELITIAN}

Populasi penelitian ini adalah seluruh pengguna brand obat OTC di Jakarta dan ditetapkan sampel sebanyak 150 responden. Metode pengambilan data yaitu non-probability sampling dengan teknik convenience sampling. Skala pengukuran menggunakan skala interval 5 poin dengan 1 menunjukkan "sangat tidak setuju" dan 5 menunjukkan "sangat setuju". Brand Awareness, perceived quality dan brand loyalty yang masing-masing memiliki jumlah indikator 4 diambil dari sumber Foroudi et al. (2018), sedangkan purchase intention memiliki jumlah indikator 3 yang diambil dari Santoso dan Cahyadi (2014). Metode analisis data yang digunakan adalah uji model persamaan struktural melalui software SmartPLS 3.2.8.

\section{HASIL PENELITIAN DAN PEMBAHASAN}

Dari 150 sampel mayoritas responden mengonsumsi brand obat OTC dalam 3 bulan terakhir $(60,0 \%)$, berjenis kelamin perempuan $(60,0 \%)$, berusia $20-35$ tahun $(89,3 \%)$, berprofesi karyawan swasta $(80,7 \%)$ dan berpendidikan terakhir Sarjana $(75,3 \%)$. Nilai Average Variance Extracted (AVE) dari masing-masing variabel tergolong valid karena skor AVE $>0,5$. Selain itu, nilai cronbach's alpha dan composite reliability dari masing-masing variabel $>0,7$ sehingga instrumen penelitian dikatakan reliable.

Berikut ini terdapat tabel yang menjelaskan hasil uji statistic sebagai berikut:

\section{Tabel 1}

\section{Hasil Pengujian Hipotesis}

\begin{tabular}{llcc}
\hline \multicolumn{1}{c}{ Hipotesis } & Coefficient & T-statistic \\
\hline $\mathrm{H}_{1}$ & Brand Awareness $->$ Purchase Intention & 0,075 & $1,101^{* *}$ \\
\hline $\mathrm{H}_{2}$ & Perceived Quality $->$ Purchase Intention & 0,111 & $1,416^{* *}$ \\
\hline $\mathrm{H}_{3}$ & Brand Awareness $->$ Brand Loyalty & 0,384 & $4,737^{* *}$ \\
\hline $\mathrm{H}_{4}$ & Perceived Quality -> Brand Loyalty & 0,367 & $4,481^{* *}$ \\
\hline $\mathrm{H}_{5}$ & Brand Loyalty $>>$ Purchase Intention & 0,657 & $10,706^{* *}$ \\
\hline $\mathrm{H}_{6}$ & Brand Awareness $->$ Brand Loyalty -> Purchase Intention & 0,253 & $4,496^{* *}$ \\
\hline $\mathrm{H}_{7}$ & Perceived Quality $->$ Brand Loyalty -> Purchase Intention & 0,241 & $3,732^{* *}$ \\
\hline${ }^{*} \mathrm{p}<0,05 ; * * \mathrm{p}<0,01$ & &
\end{tabular}

Brand awareness, perceived quality dan brand loyalty berkontribusi terhadap purchase intention sebesar 0,075, 0,111dan 0,657. Brand awareness dan perceived quality berkontribusi terhadap purchase intention sebesar 0,384 dan 0,367. Brand awareness dan perceived quality berkontribusi terhadap purchase intention dimediasi oleh brand loyalty sebesar 0,253 dan 0,241. Pada hasil uji hipotesis, brand awareness dan perceived quality tidak berpengaruh positif terhadap purchase intention karena $t$-statistics lebih kecil dari $t$-value 1,96, sedangkan brand loyalty berpengaruh positif terhadap purchase intention. Brand awareness dan perceived quality berpengaruh positif terhadap brand loyalty. Brand awareness dan perceived quality berpengaruh positif terhadap purchase intention dimediasi oleh brand loyalty. Data tersebut dibuktikan dengan $t$ statistics lebih besar dari $t$-value 1,96 sehingga kesimpulannya adalah $\mathrm{H}_{1}$ dan $\mathrm{H}_{2}$ ditolak, sedangkan $\mathrm{H}_{3}, \mathrm{H}_{4}, \mathrm{H}_{5}, \mathrm{H}_{6}, \mathrm{H}_{7}$ tidak ditolak. 
Hipotesis $\mathrm{H}_{1}$ menunjukkan brand awareness tidak berpengaruh positif terhadap purchase intention. Seseorang yang mengenal brand obat OTC belum tentu untuk tertarik melakukan pembelian di masa yang mendatang. Hal ini tidak sesuai dengan peleitian olej Monareh dan Wiryawan (2012).

Hipotesis $\mathrm{H}_{2}$ menunjukkan perceived quality tidak berpengaruh positif terhadap purchase intention. Brand obat OTC yang dipandang berkualitas tidak menjadi penentu bagi konsumen dalam melakukan pembelian di masa mendatang. Hal ini tidak sesuai dengan penelitian Bilal dan Ali (2013).

Hipotesis $\mathrm{H}_{3}$ menunjukkan brqnd awareness berpengaruh positif terhadap brand loyalty. Brand obat OTC harus memiliki karakter yang kuat yang dapat membedakannya dengan kompetitor lain sehinga dapat merangsang tingkat preferensi konsumen. Hal ini didukung oleh Dhurup et al. (2014) dan Andervazh et al. (2016)

Hipotesis $\mathrm{H}_{4}$ menunjukkan perceived quality berpengaruh positif terhadap purchase intention. Ketika konsumen mendapatkan nilai positif yang ditawarkan dari kualitas brand obat OTC, konsumen mendapatkan kepuasan akan kualitas brand karena sesuai dengan yang dipersepsikan dan dapat meningkatkan preferensi dalam penggunaan brand yang sama. Hal ini didukung oleh Foroudi et al. (2018).

Hipotesis $\mathrm{H}_{5}$ menunjukkan brand loyalty berpengaruh positif terhadap purchase intention. Semakin tinggi loyalitas konsumen terhadap brand, maka konsumen kecenderungan sulit untuk berpindah ke brand lain. Hal ini dmempengaruhi minat pembelian konsumen sendiri karena memiliki kedekatan yang kuat dengan brand tersebut. Hal ini didukung oleh Mariana dan Meilani (2017).

Hipotesis $\mathrm{H}_{6}$ menunjukkan brand awareness berpengaruh positif terhadap purchase intention jika dimediasi oleh brand loyalty. Semakin kuat karakter brand obat OTC, semakin tinggi konsumen setia terhadap brand tersebut dan meningkatkan minat pembelian. Hal ini didukung oleh Chi et al. (2014).

Hipotesis $\mathrm{H}_{7}$ menunjukkan perceived quality berpengaruh positif terhadap purchase intention jika dimediasi oleh brand loyalty. Kualitas brand menampilkan nilai yang dapat diterima dengan apa yang dipersepsikan oleh konsumen. Hal ini dapat meningkatkan kedekatan konsumen hingga membentuk loyalitas terhadap brand. Penelitian ini didukung oleh Muslim dan Qur'anis (2017).

\section{KESIMPULAN, SARAN, DAN IMPLIKASI MANAJERIAL}

Kesimpulan hasil dari penelitian menjelaskan bahwa $\mathrm{H}_{1}$ dan $\mathrm{H}_{2}$ ditolak, sedangkan $\mathrm{H}_{3}$, $\mathrm{H}_{4}, \mathrm{H}_{5}, \mathrm{H}_{6}, \mathrm{H}_{7}$ tidak ditolak Saran bagi perusahaan yaitu mebangun loyalitas merek terhadap konsumen dengan peningkatan nilai yang dimiliki baik dari karakter maupun kualitas brand itu. Saran peneliti lain diharapkan dapat menggunakan variabel lain untuk meneliti purchase intention seperti brand fondness, product country dan sebagainya untuk memberikan pandangan lebih luas dari peneltiian ini. Implikasi manajerial yang bisa diterapkan oleh perusahaan yaitu memanfaatkan kegiatan promosi berbasis internet guna memberikan pengetahuan secara luas dan lebih dalam akan brand tersebut. Mempertahankan konsistensi kualitas produk di pasaran agar konsumen tetap memiliki persepsi yang positif terhadap kualitas yang ditawarkan. Meningkatkan loyalitas konsumen untuk meningkatkan rasa puas serta kepercayaan konsumen akan brand tersebut. Besarnya kesetiaan konsumen dapat mempengaruhi intensi pembelian konsumen dalam penggunaan produk-produk dari brand di masa mendatang.

\section{DAFTAR PUSTAKA}

Aaker, David A. (2008). Strategic Market Management $8^{\text {th }}$ Edition. New York: John Wiley \& Sons, Inc. 
Bilal, Muhammad Musharraf dan Tahir Ali. (2013). Factors Influencing Consumers Purchase Intentions Towards Private Brands. Journal of Independent Studies and Research Management, Social Science and Economics, 11(2), 1-12.

Belch, George E dan Michael A. Belch. (2015). Advertising and Promotion: An Integrated Marketing Communication Perspective. New York: McGraw-Hill.

Chi, Hsin Kuang, Huery Ren Yeh dan Ya Ting Yang. (2009). The Impact of Brand Awareness on Consumer Purchase Intention: The Mediating Effect of Perceived Quality and Brand Loyalty. The Journal of International Management Studies 4(1), 135-144.

Dhurup, M., Mafini, C., dan Dumasi, T. (2014). The Impact of Packaging, Price and Brand Awareness on Brand Loyalty: Evidence from the Paint Retailing Industry. Acta Commercii, $14(1), 1-9$.

Durianto, Darmadi dkk. (2001). Strategi Menaklukkan Pasar Melalui Riset Ekuitas dan Perilaku Merek". Jakarta: PT. Gramedia Pustaka Utama.

Durianto, dan Liana. C, (2004). Analisi Efektivitas Iklan Televisi Softener Soft \& Fresh di Jakarta dan Sekitarnya dengan Menggunakan Consumen Decision Model. Jurnal Ekonomi Perusahaan,11(1), 35-55.

Foroudi Pantea et al. (2018). Percepetional Components of Brand Equity: Configuring The Symmetrical and Asymmetrical Paths to Brand Loyalty and Brand Purchase Intention. Journal of Business Research, 8, 462-474.

Karam, Asaad Ali dan Serdar Saydam. (2015). An Analysis Study if Improving Brand Awareness and Its Impact on Consumer Behavior Via Media in North Cyprus (A Case Study of Fast Food Restaurants). International Journal of Business and Social Science, 6(1), 66-80.

Khan, M.A., \& Mahmood, Z. (2012). Impact of Brand Loyalty Factors on Brand Equity. International Journal of Academic Research, 4(1), 33-37.

Keller, Kevin L. (2013). Strategic Brand Management: Building, Measuring and Managing Brand Equity ( $4^{\text {th }}$ Edition). England: Pearson Education Inc.

Mariana dan Meilani. (2017). Ekuitas Merek terhadap Intensi Pembelian Smartphone Iphone pada Mahasiswa. Jurnal Akuntansi dan Manajemen, 3 (6), 33-49.

Muslim dan Qur'anis. (2017). Strategy to Increase Customer's Purchase Intention on Garuda Indonesia's International Flights Based on Brand Equity Factors. Jurnal Manajemen Teknologi, 16(2), 124-140.

Monareh, Ria E dan Zahrida Z. Wiryawan. (2012). Pengaruh Brand Awareness terhadap Perceived Quality dan Brand Loylaty sebagai Determinan terhadap Purchase Intention. Jurnal Manajemen, 16(3), 299-311.

Selvrajah, Dilashenyi Devi. (2018). The Factor Influencing Brand Loyalty in Fashion Industry among Generation Y in Malaysia. International Journal of Business and Management, 13(4), 201-209.

Schiffman, L. dan Wisenblit, L. (2015). Consumer Behavior (11 th Edition). England: Pearson Education.

Shah et al. (2012). The Impact of Brands on Consumer Purchase Intention. Asian Journal of Business Management, 4(2) 105-110.

Santoso, Chynthia Ratnda dan Tabita Ella Cahyadi. (2014). Analyszing the Impact of Brand Equity towards Purchase Intention in Automotive Indsutry: A Case Study of ABC in Surabaya. Journal of Management, 2(2), 29-39.

Surachman, S.A. (2008). Dasar-Dasar Manajemen Merek. Malang: Bayumedia Publishing.

Tuan, Vuong khanh dan Prof Premkumar Rajagopal. (2017). The Mediating Effect of Perceived Quality on The Customer Loyalty in Small and Medium-Sized Enterprises (SMEs) in the Mobile Phone Sector in Ho Chi Minh City (HCMC) Vietnam. Intenational Journal of New Technology and Research, 3(11), 129-137.

Wu P.C.S, Yeh G.Y.Y., Hsiao C.R. (2011), The Effect of Store Image and Service Quality on Brand Image and Purchase Intention for Private Label Brands, Australian Marketing Journal, $19,30-39$. 